УДК 902/903

DOI 10.18413/2687-0967-2020-47-1-30-40

\title{
БРОНЗОВЫЕ ИЗДЕЛИЯ КРУГА ВЫЕМЧАТЫХ ЭМАЛЕЙ С ПАМЯТНИКОВ ЮГА ВОСТОЧНОЙ ЕВРОПЫ
}

\section{BRONZE ARTICLES BELONGING TO THE GROUP OF CHAMPLEVE ENAMELS FROM SITES IN THE SOUTHERN PART OF WESTERN EUROPE}

\author{
А.Ю. Колесникова, И.В. Зиньковская \\ A.Ju. Kolesnikova, I.V. Zin'kovskaya
}

Воронежский государственный университет, Россия, 394018, г. Воронеж, Университетская пл., 1

Voronezh State University, 1 Universitetskaya pl., Voronezh, 394018, Russia

E-mail: a.granuaile@gmail.com, zinkovi@yandex.ru

\begin{abstract}
Аннотация
Одними из самых ярких элементов культур римского времени лесной и лесостепной зон Восточной Европы являются бронзовые изделия с выемчатыми эмалями. Они получили свое название по характерной геометрической орнаментации, в которой широко использовались эмали разной окраски. Их набор весьма устойчив и включает украшения (браслеты, разнообразные подвески, нагрудные цепи), детали одежды (фибулы, пряжки и другие детали поясов), а также шпоры. Отдельные находки изделий круга «варварских эмалей» известны далеко от основного ареала их распространения - на Юге Восточной Европы в античных, позднескифских, сарматских могильниках. При этом, подавляющее большинство лесостепных эмалей найдены вне комплексов, или, в лучшем случае, в культурном слое. Практически все южные находки происходят, как правило, из хорошо датированных погребений. В статье рассмотрены вопросы хронологии и этнокультурной атрибуции бронзовых изделий круга выемчатых эмалей с памятников юга Восточной Европы. Эти изделия были характерны для этнического костюма «северных варваров», которые продвинулись на юг Восточной Европы и в Крым вместе с поздними сарматами в конце II - середине III в.
\end{abstract}

\begin{abstract}
One of the most striking elements of Roman period cultures in the the forest and forest-steppe zones of Eastern Europe are bronze items with champlevé enamels. They got their name by a specific geometric ornamentation, in which enamels of different colors were widely used. The set is very stable and includes: jewelry (bracelets, various pendants, chest chains), clothing parts (brooches, buckles and other belt parts) as well as spurs. Some finds of «barbaric enamels» circle are known far from the main area of their distribution - in the south of Eastern Europe in late Scythian, Sarmatian and antiquity cultures burial grounds. Moreover, if the vast majority of forest-steppe enamels are found outside the complexes or in the cultural layer, almost all southern finds come from well-dated burials. The article deals with the issues of chronology and ethnocultural attribution of bronze items belonging to the group of champlevé enamels from sites in the southern part of Eastern Europe. These articles were characteristic of the traditional costume of «northern barbarians» who moved to the southern part of Eastern Europe and Crimea together with the late Sarmatians in late $2^{\text {nd }}-$ middle $3^{\text {rd }}$ centuries A. D.
\end{abstract}

Ключевые слова: выемчатые эмали, варвары, сарматы, балты, германцы, Восточная Европа, Крым.

Key words: champlevé enamels, barbarians, Sarmatians, Balts, Germans, East Europe, Crimea. 
Одними из самых ярких элементов культур римского времени лесной и лесостепной зон Восточной Европы являются бронзовые изделия с выемчатыми эмалями. Они получили свое название по характерной геометрической орнаментации, в которой широко использовались эмали разной окраски. Их набор весьма устойчив и включает украшения (браслеты, разнообразные подвески, нагрудные цепи), детали одежды (фибулы, пряжки и другие детали поясов), а также шпоры.

Первая сводка находок предметов с выемчатыми эмалями в Восточной Европе была составлена А.А. Спицыным [Спицын, 1903, с. 149-192]. По заключению Х.А. Моора, группа украшений с выемчатыми эмалями появилась в Мазурии на рубеже I-II вв., откуда они распространились в Поднепровье и другие районы Восточной Европы [Moora, 1938, S. 110-113]. В.Н. Даниленко первым из исследователей включил эмали в состав вещей памятников киевского типа II-IV вв., и на основе позднелатенских и римских аналогий отнес их возникновение к концу II в. [Даниленко, 1955]. Серьезная попытка изучения изделий с выемчатыми эмалями была предпринята Г.Ф. Корзухиной [Корзухина, 1978], составившей в 1978 г. их свод. Местом возникновения стиля восточноевропейских эмалей она считала Юго-Восточную Прибалтику и Мазурию, а украшения с эмалью датировались ею IV-V вв. В разработку хронологии изделий круга эмалей наиболее существенный вклад внес Е.Л. Гороховский [Гороховский, 1982а], который обоснованно отнес их к середине II - началу IV в. Он не только существенно удревнил их хронологию, но и доказал связь с постзарубинецкими и киевскими древностями. Истоки «эмалевого» стиля находятся, по мнению этих исследователей, в традициях раннеримского и позднелатенского прикладного искусства, существенное влияние на его формирование в Среднем Поднепровье оказали древности Западной Литвы [Корзухина, 1978, с. 51-53; Гороховский, 1982, c. 133-144]. По мнению М.Б. Щукина, находки на постзарубинецких памятниках вещей с эмалями, подковообразных фибул серии Гришинцы - Малышки - Межонис обусловлены пронизывавшими лесную зону во II в. «балтийскими культурными импульсами», а также тесными днепро-балтийскими контактами. В результате «брожения» в лесной зоне вещи с эмалью были постепенно разнесены от Прибалтики до пограничья со степью [Щукин, 1994, с. 282-283].

Из последних работ по изделиям с выемчатыми эмалями следует выделить сводку А.М. Обломского и Р.В. Терпиловского [Обломский, Терпиловский, 2007], которые проанализировали 55 находок из лесостепной полосы Восточной Европы и обосновали их датировку 2-й половиной II в. - серединой III в. Близкую точку зрения на хронологию вещей с выемчатыми эмалями высказал А.Г. Фурасьев. Выпадение в землю многочисленных кладов с украшениями круга выемчатых эмалей он связывает с событиями 250-260-х гг., «с дестабилизацией политической ситуации в Европе, вызванной бурными миграционными процессами, возникновением черняховской культуры в Северном Причерноморье (период C1b, 230-260 гг.) и экспансией готов на земли, занятые прежде сарматами и населением киевской культуры» [Фурасьев, 2002, с. 86]. По мнению А.М. Обломского, днепровские (южные) клады с выемчатыми эмалями могли выпасть в землю в результате Скифских или Готских войн сер. III в., а верхнедонские клады выпали в результате «удара некой третьей силы», которой было черняховское население, продвинувшееся в Верхнее Подонье и оставившее в регионе памятники типа Каширки - Седелок [Обломский, 2018, c. 252-253].

По мнению О.С. Румянцевой, время возникновения стиля восточноевропейских выемчатых эмалей и существования украшений первой и второй стадий его развития совпадает с периодом расцвета провинциально-римского эмалирования на континенте, которое начинается во 2-й половине II в. и длится 1-ю половину III в.

Украшения с эмалями были произведены мастерами Римской империи специально для варварского населения Восточной Европы. Отливка металлических основ украшений и эмалирование могли происходить в одних и тех же мастерских и, возможно, делаться одними и теми же ремесленниками. В сер. III в. в римских провинциях на Дунае происхо- 
дит упадок эмалирования, что повлекло за собой прекращение экспорта изделий с выемчатыми эмалями [Румянцева, 2018, с. 222-226].

В последнее время стали известны новые районы концентрации изделий круга выемчатых эмалей: в Подонье [Зиньковская, 2011; Обломский, 2018], в Среднем Прихоперье в древностях «инясевского типа» II в. - середины III в. [Хреков, 2012, Хреков, Шуваев, 2016; Зиньковская, 2019]. Отдельные находки изделий круга «варварских эмалей» известны далеко от основного ареала их распространения - на Юге Восточной Европы, в античных, позднескифских, сарматских могильниках [Зиньковская, 2009; Обломский, 2017]. При этом, если подавляющее большинство лесостепных эмалей найдены вне комплексов или, в лучшем случае, в культурном слое, практически все южные находки происходят, как правило, из хорошо датированных погребений. Остановимся на них подробнее.

1. Бедражи Нои, Молдавия. Из погр. 5 кург. 8 позднесарматского могильника происходит подковообразная фибула со вставками красной эмали на концах (рис. 1:1). По Е.Л. Гороховскому, она относится к типу 2 серии III фазы А его схемы относительной хронологии подковообразных фибул, т. е. к ранней стадии эволюции вещей с эмалями [Гороховський, 1982, с. 25-28]. Вместе с фибулой в захоронении найдены наконечник ремня и бронзовая пряжка [Kurciatov, Bubulici, 1997, p. 224, fig. 3,1]. Наконечник ремня фасетированный, одночастный, слегка сужен книзу, относится к типу Н3а по В.Ю. Малашеву. Пряжка с овальной рамой, слегка прогнутым язычком без выступов и фасетированным округлым щитком близка к типу П2б по В.Ю. Малашеву. Эти вещи датируются концом II в. - III в. [Малашев, 2000, с.195-208].

2. Дивизия, Буджск, Украина. В позднесарматском женском погр. 1. кург. 2 у левого плеча скелета найдена подковообразная фибула без иглы с ромбическими гнездами для эмали на круглых окончаниях и прямоугольным гнездом с двумя сегментами по бокам на корпусе (рис. 1:2) [Субботин, Дзиговский, 1990, с. 2-4, рис. 3]. У правого плеча скелета была найдена лучковая подвязная двучленная фибула. В этом захоронении обнаружены другие бронзовые вещи: позднесарматское зеркало-подвеска типа Хазанов IX с тамгообразным знаком боспорского царя Ининсимея Боспорского (234-239), фасетированный наконечник ремня, а также застежка-зажим («бигуди»). Погребение позднесарматское, по мнению А.А. Васильева и О.К. Савельева, оно датируется 240-270 гг. [Васильев, Савельев, 2008, с. 32-36].

3. Красный Маяк, Украшна. В позднескифском могильнике в погр. 48 в грунтовой овальной яме, ориентированной по линии С3-ЮВ, были найдены останки двух младенцев, возрастом от 6 месяцев до полутора лет, которые лежали вытянуто на спине, головой на северо-запад. Отдельные кости имели следы обожженности [Гей, Бажан, 1993, с. 52-58, рис. 3]. В районе черепа первого ребенка находился бронзовый проволочный налобный венчик, диаметром 11,5 см, с замком в виде двух крючков, один из которых заканчивается конической шишкой. Передняя часть венчика расплющена в ромбическую пластину, орнаментированную пуансоном (рис. 1:3). Здесь же обнаружены бронзовые колечки из тонкой проволочки диаметром 1,6 - 1,8 см и три бронзовые трубочки-пронизки длиной $0,8-2,5$ см. Эти украшения вместе с налобным венчиком представляли элементы единого головного убора, типа вайнаги. Аналогии налобному венчику известны в культурах Прибалтики и лесной зоны Восточной Европы II в. В погребении была найдена бронзовая круглопроволочная одночленная лучковая фибула, длиной 6 см, с трапециевидной ножкой и длинной обмоткой корпуса. По В.В. Кропотову, эта фибула входит в серию 1 варианта 4 формы 1 и датируется концом II в. - 1-й половиной III в. [Кропотов, 2010, с. 80, 110]. Кроме этого были обнаружены: бронзовая фибула длиной 3,3 см, с пластинчатой спинкой, украшенной пуансонным орнаментом и завитком на конце приемника, а также два бронзовых пирамидальных колокольчика высотой 1,8-2 см, три спиральных кольца, изготовленных из бронзовых пластин, диаметром 0,8-1 см. На кисти левой руки был обнаружен бронзовый спиральный браслет диаметром 4 см с расплющенными и орнаментированными концами. Справа от скелета находился еще один бронзовый спиральный браслет диаметром 3,5 см из массивного овального в сечении стержня, концы которого 
были расплющены и оформлены в виде «змеиных головок». В районе груди были найдены разнообразные бусы.

Около черепа второго младенца были найдены обломки бронзового колечка, бронзовой ворворки и железные обоймочки, скреплявшие ремешок вокруг головы, бусины. На месте левой руки находился бронзовый браслет диаметром 3,4 см, изготовленный из прямоугольного в сечении стержня, один конец его был расплющен и орнаментирован.

По мнению О.А. Гей и И.А. Бажан, погребение датируется 2-й половиной II в. - 1-й половиной III в. Такие элементы погребального обряда, как тип погребального сооружения (простая грунтовая яма с каменной стелой), наличие фрагмента челюсти лошади, расчлененность костяков имеют истоки в культурах римского времени в Прибалтике. Комплекс свидетельствует о наличии в составе населения Нижнего Поднепровья накануне эпохи «Готских» войн и появления здесь черняховской культуры чужеродного компонента, связанного своим происхождением с балтским миром [Гей, Бажан, 1993, с. 55-58].

4. Валовый 1, Нижний Дон. В подбойной женской могиле кургана 33 лежал скелет головой на север, череп слегка деформирован. Слева от правой ноги были найдены три бронзовых изделия с выемчатыми эмалями. Два из них однотипные - крестовидной формы, на пересечении лучей имеется крестовидное углубление, заполненное красной эмалью (рис. 1: 4, 5). От трех лучей отходят полумесяцы, концы которых завершаются расширениями в виде дисков. Диски украшены крестообразными углублениями, заполненными желтой эмалью. На четвертом луче имеется литой вертикальный сегмент, выше его стержень обломан. Размер $6 \times 5$ см. Третье изделие в виде стилизованного солярного знака украшено красной эмалью (рис. 1:6). Его основу составляет круг с мальтийским крестом внутри, от круга отходят лучи, завершающиеся крестовидными фигурами, их три конца оформлены в виде конических утолщений. Размер 6×6,5 см. Оно является круглым звеном нагрудной цепи.

В погребении также были найдены: лучковая подвязная одночленная фибула 5 варианта и сильно профилированная фибула причерноморского типа (1 тип, 2 вариант), литой бронзовый котел, бронзовое китайское зеркало, набор украшений и посуды. Погребение - позднесарматское, скорее всего, датируется рубежом II-III вв. [Беспалый, Беспалая, Раев, 2007, с. 80-81].

5. Клин-яр, г. Кисловодск. В погр. 11 в грунтовой могиле найден скелет женщины, положенной вытянуто, на спине, головой на юго-запад. При ней найдена железная пряжка с округлой рамкой и подвижным язычком, бронзовая фибула и бронзовая подвескалунница треугольной формы, окончания которой украшены тремя кружочками с эмалью. По обрядовым признакам (кисти рук на тазовых костях, ноги перекрещены в голенях) захоронение позднесарматское. Бронзовая сильно профилированная фибула причерноморского типа (тип 1, вариант 2) позволяет датировать его 2-й половиной II в. [Виноградов, Рунич, 1969, с. 118-119].

6. Kепb, Краснодарский край. Погр. из раскопок Н.И. Сокольского 1962 г. было впущено в культурный слой, поэтому тип могилы не установлен. Скелет женщины лежал вытянуто, на спине, головой на юго-запад, а кисти ее рук находились на нижней части живота. При ней найден фрагмент бронзовой треугольной фибулы (эмаль не сохранилась) (рис. 1:7), лежавшей выше левого плеча, а также бронзовое зеркало, находившееся на правой части груди. Зеркало на обороте было украшено рельефным орнаментом из концентрических кругов и полукружий. По описанию Н.И. Сокольского, оно имеет «короткую боковую ручку без дырочки» [Сокольский, 1964, с. 207-209, рис.1, 2], хотя в публикации на фотографии она заметна. Если это так, то оно является сарматским зеркалом-подвеской с боковой петлей, типа Хазанов IX. В таком случае, погребение следует датировать 2-й половиной II в. - серединой III в.

7. Нейзац, Крым. В склепе № 275 на тазовых костях одного из погребенных найдена бронзовая ажурная плакетка. Она завершается кольцом, украшенным изображением ушастого животного. Поверхность орнаментирована зигзагообразными линиями (рис. 1:8). Размеры 
плакетки 10,1×2,4 см. По мнению И.Н. Храпунова, плакетка была частью нагрудной цепи. Вероятно, она использовалась как украшение, а настоящее ее предназначение неизвестно [Храпунов, 2011, с. 47-48, рис. 40, 4]. В женских и детских погребениях III в. были обнаружены бронзовые пластинки, украшенные пуансонным орнаментом, с загнутыми краями. В погр. 174 таких пластинок было найдено 10 экз., в погр. 59 - 7 экз. В тех случаях, когда бронзовые пластинки находятся in situ, они лежат на черепах. Иногда под ними сохраняется полоса кожаного тлена. По мнению И.Н. Храпунова, пластинки являлись деталями головного убора кожаных ремешков, на котором в ряд, в нескольких см друг от друга, крепились бронзовые пластинки [Храпунов, 2011, с. 37, рис. 34, 5-14].

8. Чaтыр-Даг, Крым. В погр. 15 в каменном ящике с кремацией были найдены изделия из бронзы: фрагмент крупной перекладчатой фибулы (рис. 1:9), пряжка с овальным щитком и железным язычком (тип П2а, конец II в. - III в. по В.Ю. Малашеву), бронзовая бляшка с отверстием в центре и пуансонным орнаментом, обломок круглопроволочного браслета, две подвески из сильно истертых боспорских монет с отверстиями у краев [Мыц и др., 2006, с.15, табл. 19а]. Погр. 15 датируется концом II в. - III вв.

В погр. 14 в каменном ящике размером 0,6×0,34 м, с кремацией, были найдены предметы личного убора, изготовленные из бронзы. Прежде всего следует обратить внимание на 6 прямоугольных с загнутыми краями накладок, украшенных пуансонным орнаментом, являвшихся элементами головного убора (венца) [Мыц и др., 2006, таб. 17, 1]. Они аналогичны пластинкам, найденным в погр. Нейзац. Кроме этого в погр. были найдены другие бронзовые изделия: 2 несомкнутых браслета с расширяющимися концами, 2 пластинчатых браслета, браслет четырехгранный в сечении, обломок ложновитой гривны, 2 перстня, 6 колокольчиков, 3 пряжки с овальным щитком, а также фаянсовые и стеклянные бусы, 2 медные истертые боспорские монеты II-III вв. и серебряная римская III в. [Мыц и др., 2006, с.15]. Из орудий труда найдены: 2 ножа, 1 игла, 2 обоймицы для игл. По мнению исследователей, погр. 14 датируется сер. III в. [Мыц и др., 2006, с. 158].

9. Херсонес, некрополь, Крым. В погр. 3 в каменном ящике в 1891 г. было обнаружено коллективное захоронение в нескольких урнах. Были найдены две треугольные фибулы с эмалью красного и зеленого цветов (рис. 1:10,11). Они относятся к типу III, варианту 1 по типологии Г.Ф. Корзухиной [Корзухина, 1978, с. 24, 77, табл. 23, 1,2]. Также были найдены серебряная монета Каракаллы (212-217), переделанная в подвеску, и две фибулы-цикады. Гробница использовалось с сер. ІІІ в.

10. Скалистое III, Крыш. В погр. 28 вместе с мечом и набором воинского снаряжения рядом с погребенным найдены две бронзовые, украшенные красной эмалью, шпоры (рис. 1:12,13). Они принадлежат подгруппе Е по классификации Е. Гинальского [Ginalski, 1991, S. 59-64]. Из погр. также происходят удила, кувшин и краснолаковая тарелка, три браслета, пять фибул, бусы, колечко с шишечками по ободу, две поясные пряжки, два наконечника ремней. Погр. 28 - единственное в некрополе воинское, всадническое погребение. По набору фибул: смычковые II в. - 1-й половины III в., лучковая подвязная 1-й половины III в. [Кропотов, 2010, с. 148, 180], погребение датируется 1-й половиной III в.

Таким образом, все проанализированные нами южные комплексы с бронзовыми изделиями круга выемчатых эмалей могут быть датированы концом II в. - серединой III вв. Большинство из них - женские (или девичьи), что хорошо согласуется с атрибуцией подвесок и сюльгам с эмалями как украшений и деталей женского костюма. Одно погребение (п. 28 Скалистое III), содержащее предметы снаряжения всадника - шпоры, - вероятно, мужское.

По погребальному обряду рассмотренные погребения с изделиями круга эмалей делятся на три группы: 1) ингумации, 2) ингумации со следами обожженности костей, 3) кремации в каменных ящиках. Среди ингумаций по погребальному обряду и инвентарю можно выделить позднесарматские погребения (к. 33 Валовый 1, п.11 Клин-яр, Кепы (1962), п. 275 Нейзац). Четыре погребения с ингумациями (п. 48 Красный Маяк, п. 28 Скалистое III, п. 59 и п. 174 Нейзац), а также три погребения с кремациями в каменных ящи- 
ках (п. 14, 15 Чатыр-Даг, п. 3 Херсонес) оставлены варварами, чья этническая атрибуция вызывает в настоящее время дискуссии. Рассмотрим основные три гипотезы:

1) «Сарматская». А.М. Обломский отметил, что находки вещей с эмалями в степях Причерноморья и в Крыму имеют близкие аналогии не в Прибалтике, а, прежде всего, в Поднепровье. В степях и в Крыму они локализуются в районах концентрации сарматских памятников и появились не в результате какого-то определенного импульса, а поступали в течение длительного времени благодаря мобильному сарматскому населению, которое являлось посредником между лесостепью и степью [Обломский, 2017, с. 64-65].

2) «Германско-балтская». По мнению В.Л. Мыца, А.В. Лысенко, М.Б. Щукина, О.В. Шарова, погребения с кремациями в каменных ящиках оставлены группой германских воинов-профессионалов, выходцев из Скандинавии. «Регион, где есть погребения в урне в каменном ящике с оружием, охватывает значительную часть Скандинавии» [Шаров, 2019, c. 337]. Спецификой этих погребений является помещение с останками кремаций оружия, а также топоров, мотыг, серпов. Такая традиция отсутствует в Крыму и на Кавказе. Судя по вещам круга эмалей, путь этой германской группы из Скандинавии пролегал через Прибалтику. Среди германцев были и отдельные представители балтских племен [Мыц и др., 2006, c. 186]. Балтской является традиция ношения женских головных уборов с бронзовыми пластинами. Их аналогии исследователи находят среди ранних латгальских венцов III в. Появление этой традиции связано с притоком в Крым нового населения из Прибалтики во 2-й половине II в. - 1-й половине III вв. При этом балтская волна предшествовала готской волне переселенцев и отчетливо проявляется в мужской субкультуре [Мыц и др, 2006, с. 158, 186]. В последней своей работе О.В. Шаров уже не выделяет отдельную балтскую волну, предшествующую готской волне: «в движении «готов» в Причерноморье приняли участие различные германские и негерманские народы и племена. Если это движение началось в Скандинавии, нетрудно понять, откуда взялись черты балтской и пшеворской культуры» [Шаров, 2019, с. 337]. По мнению О.В. Гопкало и А.С. Милашевского, специфический обряд погребения в ямах, обложенных каменными плитами, известный по черняховским могильникам (Городница, Чернелив-Русский 265), имеет провинциально-римское происхождение [Гопкало, Милашевский, 2017, с. 45].

3) «Балтская». По мнению М.В. Любичева, вещи стиля «выемчатых эмалей» являются маркером связей с Балтией. «Их появление в Восточной Европе является как отражением распространения определенной моды, торговых связей, так и индикатором продвижения групп населения» [Любичев, 2019, с. 180]. И.Н. Храпунов балтскими вещами считает плакетку из мог. Нейзац, перекладчатые фибулы из мог. Чатыр-Даг и некр. Херсонеса, шпоры с эмалью из мог. Скалистое III [Храпунов, 2011, с. 48]. О.А. Гей, И.А. Бажан и С.В. Воронятов считают комплекс вещей круга эмалей из п. 48 Красный Маяк балтским [Гей, Бажан, 1993, с. 55-58; Воронятов, 2018, с. 14]. По мнению С.В. Воронятова, ювелирная традиция, представленная пластинчатыми изделиями круга выемчатых эмалей, была принесена в Среднее Поднепровье мигрантами из Южной Прибалтики (носители культур западнобалтского круга), которые приняли участие в формировании постзарубинецких древностей [Воронятов, 2018, с. 6]. В.Е. Родинкова, проанализировав головные венчики из п. 48 мог. Красный Маяк и крымских могильников, пришла к выводу, что все они имеют не западнобалтское происхождение (летто-литовские территории), а восточнобалтское - это мощинская и дьяковская культуры, с территории которых они и проникали в Крым [Родинкова, 2018, с. 70].

Все проанализированные нами южные комплексы с вещами круга выемчатых эмалей по способу их использования можно разделить на две группы:

1) «поздние сарматы». В погребениях с ингумациями и типичным сарматским инвентарем найдены единичные вещи круга эмалей, поврежденные или использованные не по назначению, а как вещи престижа (п. 5 к. 8 Бедражи Нои, п. 1 к. 2 Дивизия, к. 33 Валовый, п. 11 Клин-яр, Кепы, п. 275 Нейзац).

2) «северные варвары». В погребениях по обряду ингумации, или ингумации с обожженными костями, или по обряду кремации вещи круга эмалей были частью этнического ко- 
стюма (парные фибулы) (п. 3 Херсонес), либо этнического головного убора (налобный венчик) (п. 59, п. 174 Нейзац, п. 14 Чатыр-Даг, п. 48 Красный Маяк), либо снаряжения всадника (шпоры) (п. 28 Скалистое III). Некоторые из погребений были совершены по обряду кремации, что нехарактерно для сарматского населения. Тем не менее расположение этих погребений на сарматских некрополях (например, Нейзац) свидетельствует о тесных связях этих «северных варваров» именно с поздними сарматами.

Таким образом, можно предположить, что т. н. «северные варвары», для этнического костюма которых были характерны бронзовые изделия круга выемчатых эмалей, продвинулись на юг Восточной Европы и в Крым вместе с поздними сарматами в конце II в. середине III вв.
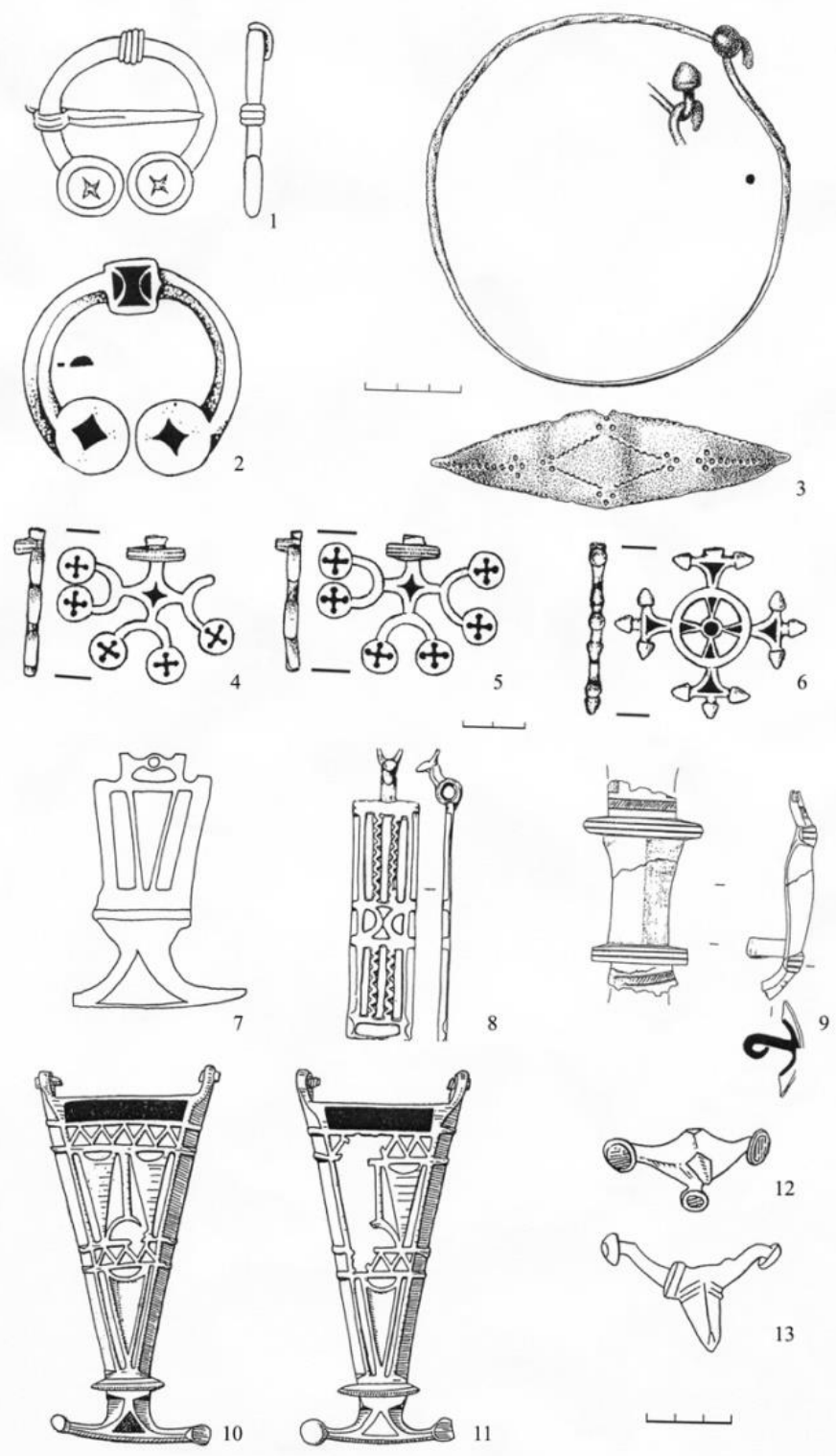

Рис. 1. Бронзовые изделия круга выемчатых эмалей с памятников юга Восточной Европы

1 - п. 5 к. 8 Бедражи Нои, 2 - п.1. к. 2 Дивизия, 3 - п. 48 Красный Маяк, 4,5,6 - к. 33

Валовый 1, 7 - п. 1962 г. Кепы, 8 - п. 275 Нейзац, 9 - п. 15 Чатыр-Даг, 10,11 - п. 3 Херсонес, 12,13 - п. 28 Скалистое III

Fig. 1. Bronze ware of a circle of notched enamels from the monuments of the south of Eastern Europe 1 - p. 5 k. 8 Bedrazhi Noi, 2 -p.1.k. 2 Diviziya, 3 -p. 48 Krasnyj Mayak, 4,5,6-k. 33 Valovyj 1, 7 -p. 1962 g. Kepy, 8 - p. 275 Nejzac, 9 - p. 15 Chatyr-Dag, 10,11 - p. 3 Hersonesos, 12, 13 - p. 28 Skalistoe III 


\section{Список литературы}

1. Беспалый Е.И., Беспалая Н.Е., Раев Б.А., 2007. Древнее население Нижнего Дона. Курганный могильник «Валовый 1» (МИА Юга России. № 2). Ростов-на-Дону, 186.

2. Васильев А.А., Савельев О.К., 2008. Переход от начального к финальному этапу позднесарматской культуры в междуречье Днестра и Дуная. Древности Центральной и Восточной Европы эпохи римского влияния и переселения народов. Ред. О.А. Радюш, К.Н. Скворцов. Калининград, 29-43.

3. Виноградов В.Б., Рунич А.П., 1969. Новые данные по археологии Северного Кавказа. АЭС. Грозный, Т. III: 95-137.

4. Воронятов С.В., 2018. Сарматский и южно-балтийский культурные импульсы в постзарубинецких древностях горизонта Рахны-Почеп (втор. пол. I в. - нач. II в. н. э.). Автореф. дис... к.и.н. СПб., 22.

5. Гей О.А., Бажан И.А., 1993. Захоронение с комплексом вещей круга эмалей на Нижнем Днепре. ПАВ. 3: 52-59.

6. Гопкало О.В., Милашевский А.С. 2017. О содержании раннего этапа культуры Черняхов - Сынтана-де-Муреш. Ранний железный век от рубежа эр до середины I тыс. н. э. Динамика освоения культурного пространства. СПб., 44-46.

7. Гороховский Е.Л., 1982. О группе фибул с выемчатой эмалью из Среднего Поднепровья. Новые памятники древней и раннесредневековой художественной культуры. Киев, 125-140.

8. Гороховский Е.Л., 1982а. Хронология украшений с выемчатой эмалью Среднего Поднепровья. Материалы по хронологии археологических памятников Украины. Киев, 125-140.

9. Даниленко В.Н., 1955. Славянские памятники I тыс. н. э. в бассейне Днепра. КСИА АН УССР. Вып.4: 27-29.

10. Зиньковская И.В., 2009. О находках изделий с выемчатыми эмалями на юге Восточной Европы. Пятая кубанская конференция: материалы конференции. Краснодар, 142-144.

11. Зиньковская И.В., 2011. О новом ареале украшений круга выемчатых эмалей. РА. 2: 72-80.

12. Зиньковская И.В., 2019. Варварские эмали в лесостепном Доно-Волжском междуречье. Вестник ВГУ. Сер. История. Политология. Социология. 3: 59-66.

13. Корзухина Г.Ф., 1978. Предметы убора с выемчатыми эмалями V в. - первой половины VI в. н. э. в Среднем Поднепровье. САИ. Вып. Е1-43, 123.

14. Кропотов В.В., 2010. Фибулы сарматской эпохи. Киев, Изд-во «АДЕФ-Украина», 383.

15. Любичев М.В., 2019. Ранняя история днепро-донецкой лесостепи I-V веков. Харьков, Издательство «Естет Принт», 268.

16. Малашев В.Ю., 2000. Периодизация ременных гарнитур позднесарматского времени. Сарматы и их соседи на Дону. Ред. Ю.К. Гугуев. Ростов-на-Дону, Терра: 194-232.

17. Мыц В.Л., Лысенко А.В., Щукин М.Б., Шаров О.В., 2006. Чатыр-Даг - некрополь римской эпохи в Крыму. СПб., «Нестор-История», 208.

18. Обломский А.М., Терпиловский Р.В., 2007. Предметы убора с выемчатыми эмалями на территории лесостепной зоны Восточной Европы (дополнение сводов Г.Ф. Корзухиной, И.К. Фролова и Е.Л. Гороховского). Памятники киевской культуры в лесостепной зоне России (III в. начало V в. н. э.) (Раннеславянский мир. Вып. 10). М., 113-141.

19. Обломский А.М., 2017. Украшения с выемчатыми эмалями восточноевропейского стиля в степях Причерноморья и в Крыму. РА. 1: 55-69.

20. Обломский А.М., 2018. Проблемы изучения кладов украшений с эмалями в Поднепровье и Подонье. Брянский клад украшений с выемчатой эмалью восточноевропейского стиля (III в. н. э.). М., Вологда, ИА РАН: 237-253.

21. Родинкова В.Е., 2018. Пластинчатые венчики или «диадемы» круга восточноевропейских выемчатых эмалей. Брянский клад украшений с выемчатой эмалью восточноевропейского стиля (ІІІ в. н. э.). М., Вологда, ИА РАН: 66-81.

22. Румянцева О.С., 2018. Обстоятельства возникновения, проблема организации производства и возможные причины упадка стиля восточноевропейских выемчатых эмалей (по итогам технологического анализа). Брянский клад украшений с выемчатой эмалью восточноевропейского стиля (III в. н. э.). М., Вологда, ИА РАН: 221-226.

23. Сокольский Н.И., 1964. Погребение V в. в Кепах. СА. 4: 207-209.

24. Спицын А.А., 1903. Предметы с выемчатой эмалью. ЗОРСА. T.V. СПб., Вып.: 149-192. 
25. Субботин Л.В., Дзиговский А.Н., 1990. Сарматские древности Днестро-Дунайского междуречья. Вып. 2. Курганные могильники Дивизийский и Белолесский. Киев, 40.

26. Фурасьев А.Г., 2002. Проблема датировки кладов вещей с выемчатыми эмалями. Клады. Состав, хронология, интерпретация. СПб., 83-85.

27. Храпунов И.Н., 2011. Некоторые итоги исследований могильника Нейзац. Исследования могильника Нейзац. Сб. науч. статей. Под ред. И.Н. Храпунова. Симферополь, 13-113.

28. Хреков А.А., 2012. Некоторые итоги и проблемы изучения постзарубинецких памятников. Археология Восточно-Европейской степи. Саратов, Вып. 9: 91-114.

29. Хреков А.А., Шуваев С.В., 2016. Новые находки предметов круга выемчатых эмалей на территории лесостепного Прихоперья. Археологическое наследие Саратовского края. Саратов, Вып. 14: 160-168.

30. Шаров О.В., 2019. Появление германцев и сармато-германские контакты в Крыму в позднеримскую эпоху. Крым в сарматскую эпоху (ІІ в. до н. э. - V в. н. э.). Отв. ред. И.Н. Храпунов. Симферополь, 328-340.

31. Щукин М.Б., 1994. На рубеже эр. СПб., Фарн, 324.

32. Ginalski J. 1991. Ostrogi kablakowe kultury przeworskiej. Klasyfikacja typologiczna. Przeglad Archeologiczny, 38. Wroclaw, 53-84.

33. Kurciatov S., Bubulici V., 1997. Necropola de la Badrgii Vechi si problema fazei finale a culturii sarmatice. Vestigii arheologice din Moldova. Ed. V. Dergaciov. Chisinau: Tipografia Academici de Stiinte RM., 220-234.

34. Moora H., 1938. Die Eisenzeit in Lettland bis etwa 500 n. Chs. Teil II. Analyse. Tartu, 749.

\section{References}

1. Bespalij E.I., Bespalaja N.E., Raev B.A., 2007. Drevnee naselenie Niznego Dona. Kurgannij mogilnik «Valovij 1» [Ancient population of the Lowed Don. Burial ground «Valovij 1»] (MIA Juga Rossii. №2). Rostov-na-Dony, 186.

2. Vasilev A.A., Savelev O.K., 2008. Perehod ot nachalnogo k finalnomu etapu posdnesarmatskoj kulturi v mezdurechje Dnestra i Dunaja [Transition from the initial to the final stage of Late Sarmatian culture between the Dniester and Danube]. Drevnosti Zentralnoi I Vostocnoj Evropi epohi rimskogo vlijnija i pereselenija narodov [Antiquities of Central and Eastern Europe, the era of Roman influx and migration]. Red. O.A. Raduz, K.N. Skvorzov. Kaliningrad, 29-43.

3. Vinogradov V.B., Runiz A.P., 1969. Novii Dannie po archeologii Severnogo Kavkaza [New data on archeology of the North Caucasus]. AES. Grosnij, T. III: 95-137.

4. Voronjatov S.V., 2018. Sarmatskie i juzno-baltijskie kulturnie impulsi v postzarubinezkih drevnostyah gorizonta Rahni-Pozep (vtor. pol. I v. - nac. II vv. n. e.) [Sarmatian and South Baltic cultural impulses in post-Zarubinets antiquities of the Rakhny-Pochep horizon (second half $1^{\text {st }}$ - beginning of the $2^{\text {nd }}$ century A. D.)]. Avtoreferat diss. k. i. n. SPb., 22.

5. Gej O.A., Bazan I.A., 1993. Zahoronenie s kompleksom vechej kruga emalej na Niznem Dnepre [Burial with a complex of enameled objects on Lower Dnieper]. PAV. :3: 52-59.

6. Gopkalo O.V., Milacevskij A.S. O soderzanii rannego etapa kultyri Chernyakhov-Sintana-deMurez [On the content of the early stage of Chernyakhov-Sintana-de-Murez culture]. Rannij zelesnij vek ot rubeza er do seredini I tis. n. e. Dinamika osvoenija kulturnogo prostranstva [Early celestial age from the turn of the eras to the middle And yew. not. The dynamics of the development of cultural space]. SPb., 2017, $44-46$.

7. Gorohovskij E.L., 1982. O gruppe fibul s viemchatoi emalju is Srednego Podneprovija [About the group of fibulae with champlevé enamels from the Middle The Dnieper]. Novii pamjatniki drevnej i rannesrednevekovoj hudozestvennoj kulturi [New monuments of ancient and medieval art culture]. Kiev, 125-140.

8. Gorohovskij E.L., 1982 a. Hronologia ukracenij s viimcatoi emaliu Srednego Podneprovija [Chronology of jewelry with champlevé enamels enamels from the The Middle Dnieper]. Materiali po hronologii archeologiceskih pamjatnikov Ukraini [Materials on the chronology of archaeological sites of Ukraine]. Kiev, 125-140.

9. Danilenko V.N., 1955. Slavjanskie pamjatniki I tis.n.e. v bassejne Dnepra [Slavic sites of I millennium A. D. in the Dnieper basin]. KSIA AN USSR. Vip. 4: 27-29.

10. Zinkovskaja I.V., 2009. O nahodkah isdelij s viimcatimi emaljami na juge Vostocnoi Evropi [About finds of items with champlevé enamels in the south of Eastern Europe]. Pjataja kubanskaja konferenzija: materiali konferenzii [Fifth Kuban Conference: conference proceedings]. Krasnodar, 142-144. 
11. Zinkovskaja I.V., 2011. O novom areale ukracenij kruga viimcatih emalej [About the new range of champlevé enameled jewelry]. RA. 2: 72-80.

12. Zinkovskaja I.V., 2019. Varvarskie email v lesostepnom Dono-Volzskom mezdurechie [Barbaric enamels in the forest-steppe Don-Volga interfluve]. Vestnik VGU. Ser. Istoria. Politologia. Soziologia. 3: 59-66.

13. Korsuchina G.F., 1978. Predmeti ubora s viimchatimi emaljami V v. - pervoj polovini VI v. n. e. v Srednem Podneprovie [Objects with champlevé enamels of Vth - first half of VIth century A. D. in the Middle Dnieper]. SAI. Vip. E1-43, 123.

14. Kropotov V.V., 2010. Fibuli sarmatskoj epochi. [Fibulae of the Samatian era]. Kiev, Izd-vo «ADEF-Ukraina», 383.

15. Lubicev M.V., 2019. Rannyaja istoria dnepro-donezkoi lesostepi I-V vv. [The early history of the Dnieper-Donetsk forest-steppe of the I-V centuries]. Harkov, Izdatel'stvo «Estet Print», 268.

16. Malacev V.J., 2000. Periodisazija remeslennih garniture posdnesarmatskogo vremeni [Periodization of Late Sarmatian belt sets]. Sarmati i ih sosedi na Donu [Sarmatians and their neighbors in the Don]. Rostov-n/D, Terra: 194-232.

17. Miz V.L., Lisenko A.V., Zukin M.B., Sarov O.V., 2006. Chatir-Dag - nekropol rimskoi epohi v Krimu [Chatir-Dag - necropolis of the Roman era in the Crimea]. SPb., «Nestor-Istoriya», 208.

18. Oblomskij A.M., Terpilovskij R.V., 2007. Predmeti ubora s viimchatimi emaljami na territirii lesostepnoi zoni Vostochnoi Evropi [Champlevé enameled items in the forest-steppe zone of Eastern Europe]. Pamjatniki kievskoi kulturi v lesostepnoi zone Rossii (III v. - nazalo V v. n. e.) [Monuments of Kiev culture in the forest-steppe zone of Russia (III - early V centuries A. D.)] (Ranneslavjanskij mir. Vip. 10). M., 113-141.

19. Oblomskij A.M., 2017. Ukrasenija s viimchatimi emaljami vostocnoevropeiskogo stilja v stepjah Prichernomorija i v Krimu [Jewelry with champlevé enamels of Eastern European style in the steppes of the Black Sea region and in Crimea]. RA. 1: 55-69.

20. Oblomskij A.M., 2018. Problemi isucenija kladov ukracenij s emalami v Podneprovie I Podonie [Problems of studying buries treasures with enamels in Dnieper and Don region]. Branskij klad ukrasenij s viimcatoi emalu vostocnoevropeiskogo stilja (III v. n. e.) [Branskiy treasure jewellery with oriental-style twisted enamel (3 century A. D.)]. M., Vologda, IA RAN: 237-253.

21. Rodinkova W.E., 2018. Plastinchatie venchiki ili diademi kruga vostochnoevropeiskih viimchatih emalej [Plate diadems or «tiaras» of Eastern European champlevé enamels]. Brjanskij klad ukrasenij s viimcatoi emaliju vostocnoevropeiskogo stilja (III v. n. e.) [Branskiy treasure jewellery with oriental-style twisted enamel (3 century A. D.)]. M., Vologda, IA RAN: 66-81.

22. Rumjanzeva O.S., 2018. Obstojatelstva vozniknovenija, problema organizatsii proizvodstva I vosmoznie prichini upadka stilya vostochnoevropeiskih viemchatih emalej (po itogam tehnologicheskogo analiza) [Circumstances of occurrence, the problem of production organization and possible causes of the decline in the style of Eastern European champlevé enamels (based on the results of technological analysis)]. Brjanskij klad ukrashenij s viemchatoi emaliju vostochnoevropeiskogo stilja (III v. n. e.) [Branskiy treasure jewellery with oriental-style twisted enamel (3 century A. D.)]. M., Vologda, IA RAN: 221-226. 207-209.

23. Sokolskij N.I., 1964. Pogrebenie V v. v Kepah [Burial of V century in Kepi]. SA. 4:

24. Spizin A.A., 1903. Predmeti s viemchatoi emaliu [Objects with champlevé enamels]. SORSA. T.V. SPb., Vip.1: 149-192.

25. Subbotin L.V., Dzigovskij A.N., 1990. Sarmatskie drevnosti Dnestro-Dunaiskogo mezdurechija. [Sarmatian antiquities of the Dniester-Danube interfluve area]. Vip. 2. Kurgannii mogilniki Divisijskij i Belolesskij [Kurgan burial grounds Divisian and Belolesky]. Kiev, 40.

26. Furasev A.G., 2002. Problema datirovki kladov veshej s viemchatimi emalyami [The problem of dating buried treasures with champlevé enamels]. Kladi. Sostav, hronologiya, interpretatsiya [Treasures. Composition, chronology, interpretation]. SPb., 83-85.

27. Hrapunov I.N., 2011. Nekotorie itogi issledovanij mogilnika Neizats [Some results of studies of the Neizats burial ground]. Issledovaniya mogilnika Neizats [Investigations of the cemetery Neizats]. Sb. nauc. statej. Pod red. I.N. Hrapunova. Simferopol, 13-113.

28. Hrekov A.A., 2012. Nekotorie itogi i problemi izucheniya postzarubinetskih pamjatnikov [Some results and problems of studying post-Zarubin sites]. Arheologia Vostochno-evropeiskoi lesostepi [Archeology of the East European forest-steppe]. Saratov, Vip. 9: 91-114. 
29. Hrekov A.A., Suvaev S.V., 2016. Novie nahodki predmetov kruga viemchatih emalei na territorii lesostepnogo Prihoperja [New finds of champlevé enameled objects in the forest-steppe zone of Hoper river]. Archeologiceskoe nasledie Saratovskogo kraja [Archaeological Heritage of the Saratov Territory]. Saratov, Vip. 14. 160-168.

30. Sarov O.W., 2019. Poyavlenie germanzev i sarmato-germanskie kontakti v Krimu v posdnerimskuyu epohu [The emergence of Germans and Sarmatian-Germanic contacts in Crimea in the late Roman era]. Krim v sarmatskuju epohu (II v. do n. e. - V v. n. e.) [Crimea in the Sarmatian era (II century B. C. - V century A. D.).]. Otv. red. I.N. Hrapunov. Simferopol, 328-340.

31. Schukin M.B., 1994. Na rubeze er [At the turn of the era]. SPb., Farn, 324.

32. Ginalski J. 1991. Ostrogi kablakowe kultury przeworskiej. Klasyfikacja typologiczna [Cable groynes of Przeworsk culture. Typological classification]. Przeglad Archeologiczny, 38. Wroclaw, 53-84.

33. Kurciatov S., Bubulici V., 1997. Necropola de la Bădragii Vechi si problema fazei finale a culturii sarmatice [Necropolis from Bădragii Vechi and the problem of the final phase of the Sarmatian culture]. Vestigii arheologice din Moldova. Ed. V. Dergaciov. Chisinau: Tipografia Academici de Stiinte RM., 220-234.

Moora H., 1938. Die Eisenzeit in Lettland bis etwa 500 n. Chs. Teil II. Analyse [The Iron Age in Latvia until 500 AD. Part II. Analysis]. Tartu, 749.

\section{Ссылка для цитирования статьи Link for article citation}

Колесникова А.Ю., Зиньковская И.В. 2020. Бронзовые изделия круга выемчатых эмалей с памятников юга Восточной Европы. Via in tempore. История. Политология, 47(1): 30-40.

DOI 10.18413/2687-0967-2020-47-1-30-40

Kolesnikova A.Ju., Zin'kovskaya I.V. 2020. Bronze articles belonging to the group of champleve enamels from sites in the southern part of Western Europe. Via in tempore. History and political science, 47(1): 30-40 (in Russian). DOI 10.18413/2687-0967-2020-47-1-30-40 